\title{
The variation of particle size of colloids in the overlying water due to hyporheic exchange
}

\author{
ZhongTian Zhang ${ }^{1}$, Guangqiu Jin ${ }^{1}$, Hongwu Tang ${ }^{1}$, Wenhui Shao ${ }^{1}$, Xiaorong Zhou ${ }^{2}$, and \\ Ling $\mathrm{Li}^{3}$ \\ ${ }^{1}$ Hohai University \\ ${ }^{2}$ Taizhou Water Conservancy Bureau \\ ${ }^{3}$ Westlake University
}

January 18, 2021

\begin{abstract}
Colloids are often in forms of inorganic and organic particles whose particle sizes $\left(d_{p}\right)$ are ranging from $1.0 \mathrm{~nm}$ to $10.0 \mu \mathrm{m}$. On the one hand, their transport processes in the hyporheic zone such as deposition, resuspension, clogging and release are substantially affected by hyporheic exchange. On the other hand, the existence of colloids can modify the hydraulic structure of the hyporheic zone due to clogging. Despite the general acknowledgement that particle size plays an important role in contaminant adsorption and clogging, it remains unclear how the particle size of colloids changes during their transport processes in the hyporheic zone. This study aims to investigate the variation of the particle size of colloids in the overlying water and the effects of settlement and convection-diffusion via laboratory experiment and numerical simulation. The results show that both settlement and convection-diffusion play roles in the exchange of colloids between the stream and the streambed. More specifically, settlement is the dominant factor affecting the exchange process of large-sized particles $\left(d_{p}>3.06 \mu \mathrm{m}\right)$ in the hyporheic zone as the high settling velocity dominates the outflux of colloids in the overlying water; the exchange process of small-sized particles $\left(d_{p}<\right.$ $1.10 \mu \mathrm{m})$ is more affected by convection-diffusion and some of them can be released from the streambed to the overlying water; while the exchange process of middle-sized particles $\left(1.10 \mu \mathrm{m}<d_{p}<3.06 \mu \mathrm{m}\right)$ is affected by both convection-diffusion and settlement. Thus, this study may provide important insights into the variation of the particle size of colloids in the overlying water and the effects of settlement and convection-diffusion.
\end{abstract}

\section{Hosted file}

HYP-20-0391.pdf available at https : //authorea.com/users/316972/articles/504570-the-variationof-particle-size-of-colloids-in-the-overlying-water-due-to-hyporheic-exchange

\section{Hosted file}

Fig_HYP-20-0391.pdf available at https://authorea.com/users/316972/articles/504570-thevariation-of-particle-size-of-colloids-in-the-overlying-water-due-to-hyporheic-exchange

\section{Hosted file}

Tab_HYP-20-0391.pdf available at https://authorea.com/users/316972/articles/504570-thevariation-of-particle-size-of-colloids-in-the-overlying-water-due-to-hyporheic-exchange 